\title{
Anthelmintic Activity of Millettia pachycarpa Root Bark Extract on an Intestinal Roundworm, Ascaridia galli
}

\author{
Kholhring Lalchhandama*
}

\section{Kholhring Lalchhandama*}

Department of Life Sciences, Pachhunga University College, Aizawl 796 001, Mizoram, INDIA.

\section{Correspondence}

\section{Kholhring Lalchhandama, MSc, PhD}

Associate Professor and Head, Department of Life Sciences, Pachhunga University College, Aizawl 796 001, Mizoram, INDIA.

Phone no: +91-9436198718;

E-mail: chhandama@pucollege.edu.in

History

- Submission Date: 28-08-2019;

- Review completed: 04-10-2019;

- Accepted Date: 07-10-2019.

DOI : 10.5530/pj.2019.11.221

Article Available online http://www.phcogj.com/v11/i6s

\section{Copyright}

(C) 2019 Phcogj.Com. This is an open access article distributed under the terms of the Creative Commons Attribution 4.0 International license.

\begin{abstract}
Background: Millettia pachycarpa Benth. is member of the family Fabaceae and is a wellknown traditional medicinal plant used for different health conditions. Its roots and seeds are rich in bioactive compounds such as chalcones, isoflavones and rotenoids, which are attributed to the anticancer, antiparasitic and insecticidal properties of the plant. In Mizo traditional medicine, the root bark is also used for parasitic infections. Objective: The study was designed to understand the anthelmintic efficacy and effects of $M$. pachycarpa on an intestinal roundworm, Ascaridia galli. Materials and Methods: The methanolic extract of the root bark was prepared and survival test was performed against $A$. galli. The structural effects were studied using scanning electron microscopy and histological preparations. Results: The roundworm showed extensive structural changes and damages. The cuticle showed extensive shrinkage and cracks. Lacerations and scars distorted the fine transverse rings. The mouthparts collapsed with shrunken lips and degenerated denticles. Internal tissues such as musculature and reproductive organs were also impaired. Conclusion: The findings indicate that the plant extract is effective against parasitic roundworms.
\end{abstract}

Key words: Ascaridia galli, Cuticle, Microscopy, Millettia pachycarpa, Roundworm.

\section{INTRODUCTION}

Millettia pachycarpa Benth. (family Fabaceae) is a perennial climbing shrub endemic to Southeast Asia. The roots and seeds are used in different Asian traditional practices as insecticide in agricultural farms and as fish poison in community fishing. ${ }^{1}$ In Chinese medicine, it is known as a blood tonic and haematopoietic agent. Specifically boiled and decoction prepared with eggs is consumed for the treatment of anaemia. The haematopoietic property is used in the clinical care of leukemia patients. ${ }^{2}$ Its potential use in the treatment of cancer is well established upon its antiestrogenic and anticarcinogentic activities. ${ }^{3}$

Several bioactive compounds have been reported from $M$. pachycarpa belonging to flavonoids, triterpenoids and steroids, which are attributed to different pharmacological properties. Many prenylated isoflavonoids, dihydroflanonol, chalcones and rotenoids have been identified from the seed. ${ }^{4,5}$ The root extract also yielded many rotenoids including rotenone, cis-12ahydroxyretenone, rot-2'-enonic acid, and cis-12ahydroxyrot-2'-enonic acid, as well as isoflavones, $\beta$-sitosterol, oleanolic acid, karanjin, as well as novel compounds such as pachycarin A to C..$^{6-8}$

4-Hydroxylonchocarpin and deguelin from the seeds showed strong antiinflammatory activity by inhibiting nitric oxide (NO) production, inducible NO synthase (iNOS) activity and iNOS protein expression. ${ }^{9}$ A rotenoid derivative, barbigerone, present in the root has been an established anticarcinogenic molecule. ${ }^{10,11}$ Erysenegalensein $\mathrm{E}$, isoerysenegalensein E, 6,8-diprenylorobol, furowanin A and auriculasin, millewanins G (1) and $\mathrm{H}$ (2), and furowanin B (3) are isoflavonoids from the leaves tested to have antiestrogenic activity. ${ }^{12,13}$ Chalcones such as 3-hydroxy-4methoxylonchocarpin, 4-methoxylonchocarpin, isobavachromene, and dorspoinsettifolin obtained from the seeds have antitumour activity. ${ }^{14}$ Millepachine from the seed was also effective on different cancer cells. ${ }^{15}$ These studies suggest the potential role of the plant in the treatment of cancer and immune diseases.

In India, it is found in the eastern and northeastern regions extending from West Bengal to Mizoram. Specifically, among the Mizo people of northeast India, the root bark is used for the treatment of intestinal helminthiasis. ${ }^{1}$ The anthelmintic property had been experimentally evaluated. It was shown that the ethanol extract caused dose-dependent activity on the fowl tapeworm Raillietina echinobothrida, ${ }^{16}$ which was associated with structural and biochemical alterations in the worms. ${ }^{17}$ Anthelmintic drugs are mostly helminth specific thereby limiting their usage. In this study, the plant extract was tested to see whether it is effective on different helminths by testing on the intestinal roundworm of fowl, Ascaridia galli.

\section{MATERIALS AND METHODS}

\section{Preparation of plant extract}

M. pachycarpa was collected and identified as reported earlier. ${ }^{16}$ A voucher specimen (accession number PUC-BOT-M-036) is maintained at Pachhunga University College, Aizawl, India. The root barks were thoroughly washed with deionised 
water, chopped into small pieces, and dried in an oven at $45^{\circ} \mathrm{C}$. Methanol extract was made in a Soxhlet apparatus and was concentrated in a vacuum rotary evaporator (Buchi Rotavapor ${ }^{\circledR}$ R-215). The extract was obtained as a deep brown semi-solid material, with a net yield of $0.07 \%$. It was then stored at $4^{\circ} \mathrm{C}$ for further use.

\section{Chemicals and drug}

Methanol was standard analytical grade from SD Fine-Chem Ltd, Mumbai, India. All other chemicals were also standard analytical grades obtained from HiMedia Laboratories Pvt. Ltd., Mumbai, India. Albendazole (ZENTEL') was a product of GlaxoSmithKline Pharmaceuticals Ltd., Mumbai, India.

\section{In vitro viability test}

Live roundworms, Ascaridia galli Schrank, were recovered from the intestines of local fowls (Gallus gallus Linnaeus). The worms were collected in phosphate-buffered saline (PBS) maintained at $37 \pm 1^{\circ} \mathrm{C}$ in a microbiological incubator. The worms were directly treated with the different concentrations, viz. 1.25, 2.5, 5, 10 and $20 \mathrm{mg} / \mathrm{ml}$, of the plant extract (prepared in PBS with 1\% DMSO) in separate Petri dishes. Similar treatment was performed for albendazole as a reference drug, and one group was maintained in a medium containing only PBS with $1 \%$ DMSO as control. The onset of paralysis, i.e. complete loss of motor activity when agitated, was noted as the duration of survival. Each test was performed in three replicates.

Data were presented as means plus or minus the standard deviation of the mean $( \pm \mathrm{SD})$. The values were compared by Student's $t$-test, and the level of significance taken at $p<0.05$.

\section{Scanning electron microscopy}

Worms treated with $20 \mathrm{mg} / \mathrm{ml}$ of the plant extract were selected for scanning electron microscopy. After complete treatment, they were immediately fixed in $10 \%$ cold-buffered formaldehyde at $4^{\circ} \mathrm{C}$ for $4 \mathrm{~h} .0 .1$ $\mathrm{M}$ sodium cacodylate ( $\mathrm{pH}$ 7.2.) was used as buffer. Secondary fixation was done with $1 \%$ osmium tetroxide $\left(\mathrm{OsO}_{4}\right)$ buffered using the same buffer at $4^{\circ} \mathrm{C}$ for $1 \mathrm{~h}$. The fixed specimens were dehydrated through ascending concentrations of acetone up to pure acetone. They were then treated with tetramethylsilane, $\mathrm{Si}\left(\mathrm{CH}_{3}\right)_{4}$, for 15 minutes and left to dry in air-drying chamber at $25^{\circ} \mathrm{C}$. They were mounted on metal stubs and sputter coated with gold in JFC-1100 (JEOL Ltd., Tokyo, Japan) ion sputtering chamberand, Finally, they were observed under a JSM-6360 scanning electron microscope (JEOL Ltd., Tokyo, Japan) at an electron accelerating voltage of $20 \mathrm{kV}$.

\section{Histology}

Roundworms treated with $20 \mathrm{mg} / \mathrm{ml}$ of the plant extract were fixed in Bouin's solution (a mixture of acetic acid, formaldehyde, and 2,4,6-trinitrophenol) overnight. Females were selected as they possess more elaborate anatomical structures. After completely removing the fixative under running tap water, the specimens were dehydrated through a series of graded alcohols up to absolute ethanol. They were treated with a mixture of xylene and clove oil and cleared in pure xylene. Paraffin blocks were made, and sections were cut at 7-9 $\mu \mathrm{m}$ thickness. The sections were then deparaffinised with xylene, dehydrated, doubly stained with eosin and haematoxylin, and finally mounted on glass slides. Photomicrographs were taken with Zeiss image analyser HBO 50

\section{RESULTS}

The efficacy of the $M$. pachycarpa root bark extract and albendazole on the roundworm A. galli is represented in Table 1. Worms in control media survived up to $83.13 \pm 2.06$ hours. Both the drug and plant extract showed concentration-dependent activity. Albendazole was more active than the plant extract. The plant extract at lowest concentrations $(1.25$ and $1.5 \mathrm{mg} / \mathrm{ml})$ failed to exert any significant $(p>0.05)$ effect.

Figure 1 is a scanning electron microscopic image of normal $A$. galli focusing the anterior portion of the body. The apical mouth is surrounded by three lips arranged radially. Each lip is lined with fine saw blade teeth-like structures called denticles. Eye spot-like protuberance on each lip is a sensory organ called labial papilla. The general body surface is composed of a hard cuticle, which is a syncytial layer of different proteins. Cuticle on the lips are smooth while those on the body proper are creased with transverse rings around the cylindrical body. The transverse rings are actually made up of concentric layers of alternating ridges and grooves. The ridges are known as striations and the grooves as annulations. Striations and annulations are arranged in smooth and uninterrupted series.

Structural deformations are very distinct on the roundworm treated with $M$. pachycarpa root bark extract. The cuticle is clearly damaged as indicated by shrinkage and folds as if the whole body is deflated (Figure 2). The lips are shrunk and collapsed showing loss of integrity and function (Figure 3). On the body proper, the cuticle is wrinkled and irregularly depressed and appear as having several cracks (Figure 4). The fine annulations and striations are completely obliterated. Lines of cracks are running longitudinal and diagonal to the body, making laceration-like breaks, which indicate loss of flexibility and turning brittle. Scars are also seen at some points indicating direct destruction of the cuticular proteins.

Transverse section of a normal female roundworm shows a circular body as in Figure 5. The cuticle is thick, indicating a syncytium of many protein fibres. The cuticle is formed from a syncytial epidermis, which lies beneath. Internally, the epidermal layer is attached to a thick muscle layer. The musculature consists of fibrillar and protoplasmic

Table 1: Comparative efficacy of albendazole and an extract of $M$. pachycarpa root bark on the roundworm A. galli.

\begin{tabular}{|c|c|c|c|c|}
\hline Media & Dose (mg/ml) & Survival time in $\mathrm{h}( \pm \mathrm{SD})$ & t value & $p$ value \\
\hline Control & 0 & $83.13 \pm 2.06$ & - & - \\
\hline \multirow[t]{6}{*}{ Albendazole } & 1.25 & $38.83 \pm 2.26$ & 27.31 & $0.0051^{*}$ \\
\hline & 2.5 & $28.00 \pm 1.59$ & 36.71 & $0.0003^{*}$ \\
\hline & 5 & $21.13 \pm 1.45$ & 42.62 & $0.0002^{*}$ \\
\hline & 10 & $15.97 \pm 1.69$ & 42.70 & $0.0002^{*}$ \\
\hline & 20 & $11.37 \pm 1.59$ & 47.71 & $0.0001^{*}$ \\
\hline & 1.25 & $82.87 \pm 1.93$ & 00.16 & 0.9779 \\
\hline \multirow[t]{4}{*}{ Millettia pachycarpa } & 2.5 & $82.93 \pm 1.55$ & 00.13 & 0.9886 \\
\hline & 5 & $76.60 \pm 1.77$ & 04.82 & $0.0086^{*}$ \\
\hline & 10 & $70.17 \pm 1.63$ & 09.76 & $0.0006^{*}$ \\
\hline & 20 & $63.80 \pm 1.25$ & 16.11 & $0.0008^{*}$ \\
\hline
\end{tabular}

*Significant difference $(p<0.05)$ in comparison with control $(0)$ group; $n=6 ; d f=2$. 


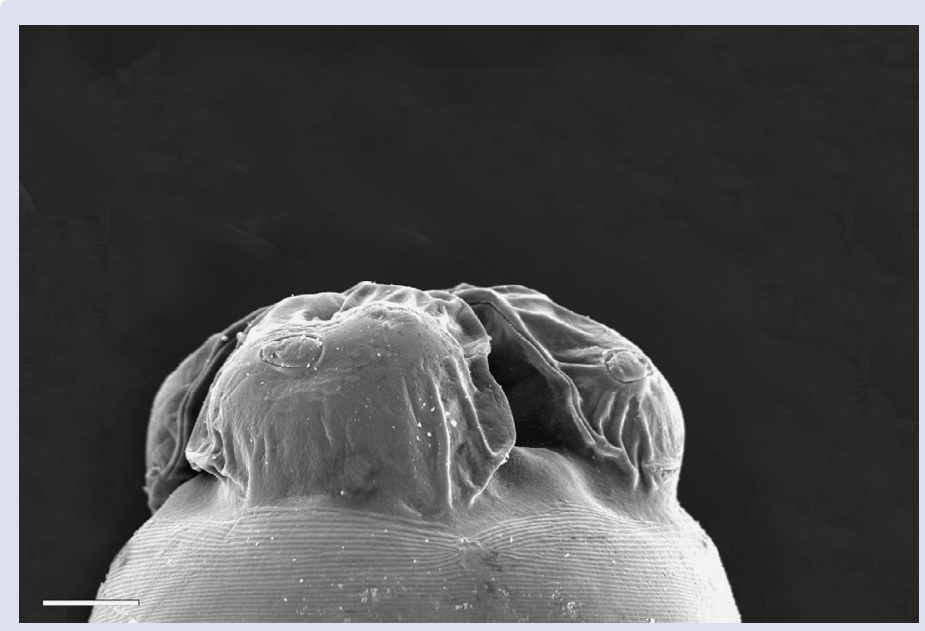

Figure 1: Scanning electron micrograph of normal A. galli. Anterior portion shows three denticulate lips surrounding the mouth, and the cuticle with distinct ridges and furrows throughout the body $(x 175$, scale bar $=100 \mu \mathrm{m})$.

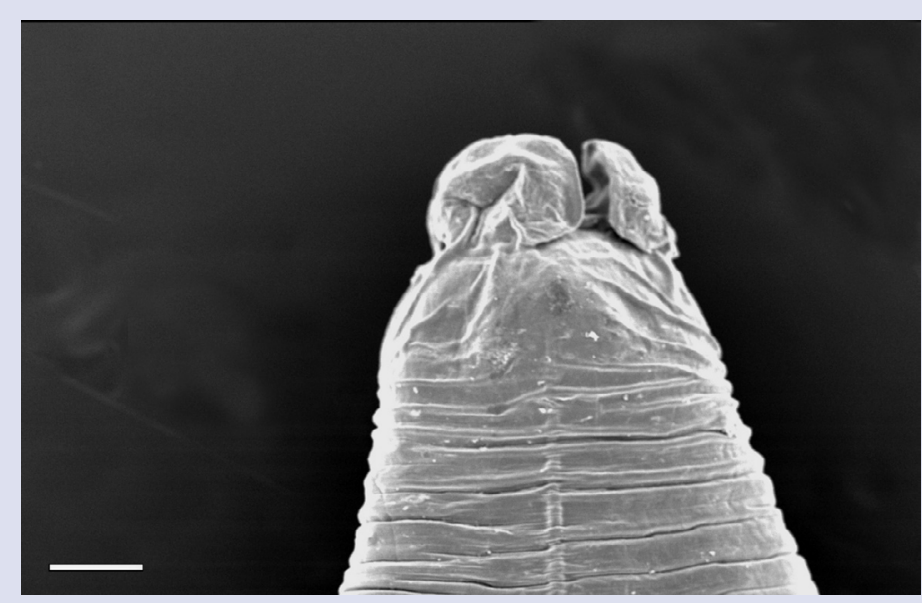

Figure 2: Anterior part of $A$. galli treated with $M$. pachycarpa root bark extract. General shrinkage of the body and collapsed lips are noticeable ( $x 80$, scale bar $=200 \mu \mathrm{m})$.

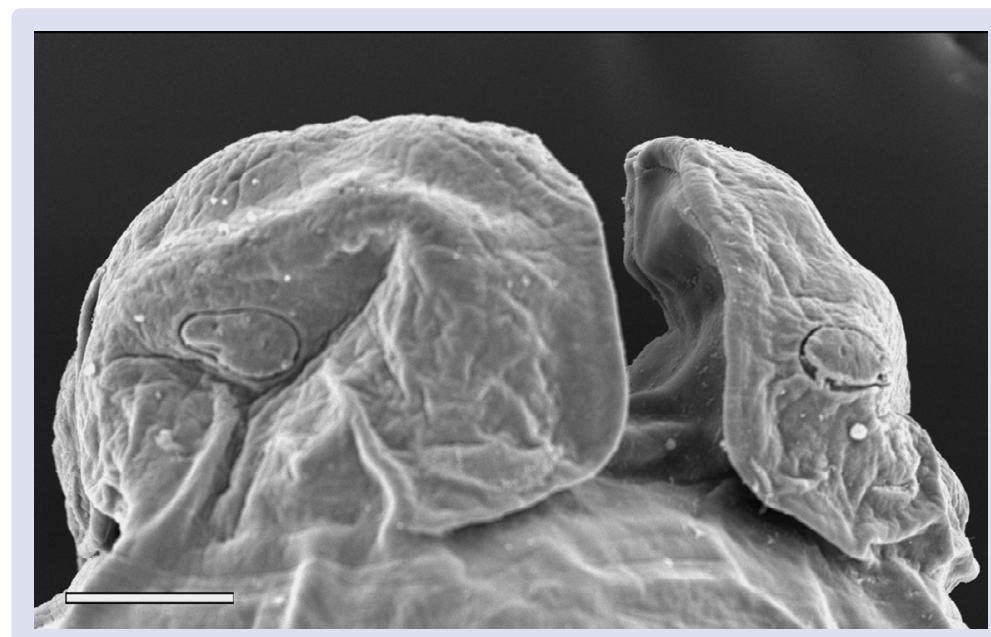

Figure 3: Mouthparts of A. galli treated with M. pachycarpa root bark extract. Shrunken lips with deflated cuticle on both inner and outer sides are evident ( $\mathrm{x}$ 170 , scale bar $=100 \mu \mathrm{m})$. 
muscles. The protoplasmic muscle layer is surrounded by a body cavity, pseudocoel. The intestine with a triangular lumen is located at the centre.

Anatomy of female roundworm treated with the plant extract shows extensive deformity as presented in Figure 6. The cuticular layer as some points are disjointed. The underlying musculature also breaks up. Ovarian tissue is also damaged. Vacuolisation is evident in the uterine chambers that contain developing and mature eggs. The mature eggs in particular can be noticed randomly distributed implying that the uterine wall completely ruptured.

\section{DISCUSSION/CONCLUSION}

Roundworms are unique animals in that their cuticle not only serves as a protective layer between the anatomical parts and the external environment, but also functions as a resilient exoskeleton which maintains the normal cylindrical shape of the body. ${ }^{18}$ As such it acts as an effective barricade from external factors such as chemicals and digestive enzymes of the host for an effective parasitic adaptation. In contrast to other helminths such as tapeworms (cestodes) and flukes (trematodes), roundworms have mouth and digestive system so that they are capable

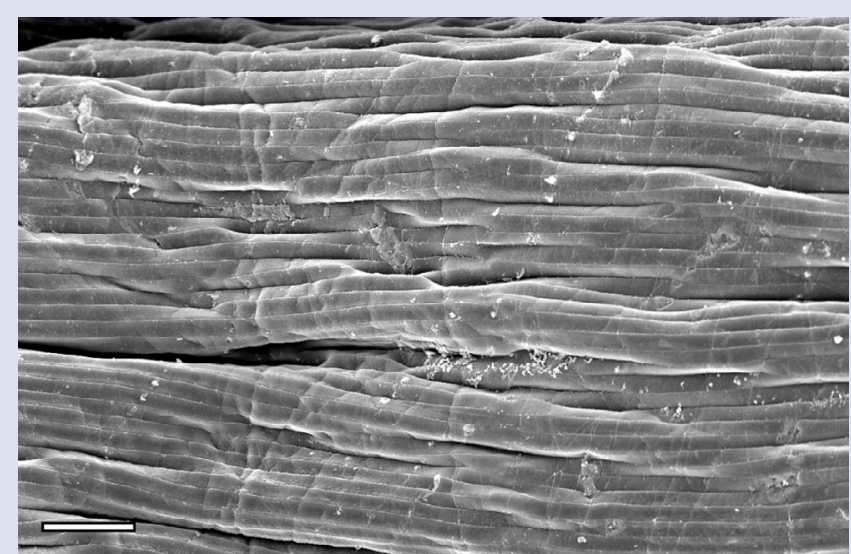

Figure 4: Body surface of $A$. galli treated with $M$. pachycarpa root bark extract. Disorganised transverse rings (annulations and striations) and some scars are visible. $(x 170$, scale bar $=50 \mu \mathrm{m})$.

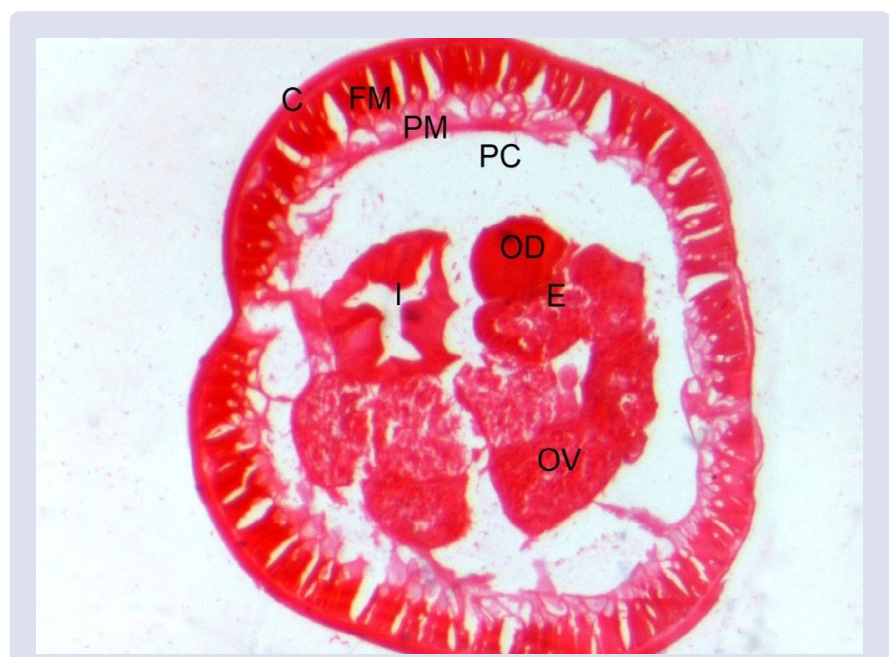

Figure 5: Transverse sections of normal female $A$. galli. Body surface cuticle (C) is surrounded by fibrillar muscle (FM) and protoplasmic muscle (PM). Ovary (OV) containing numerous oogonia, oviduct (OD), eggs $(E)$ inside uterus and intestine $(I)$ are present in the pseudocoel (PC) (x 200).

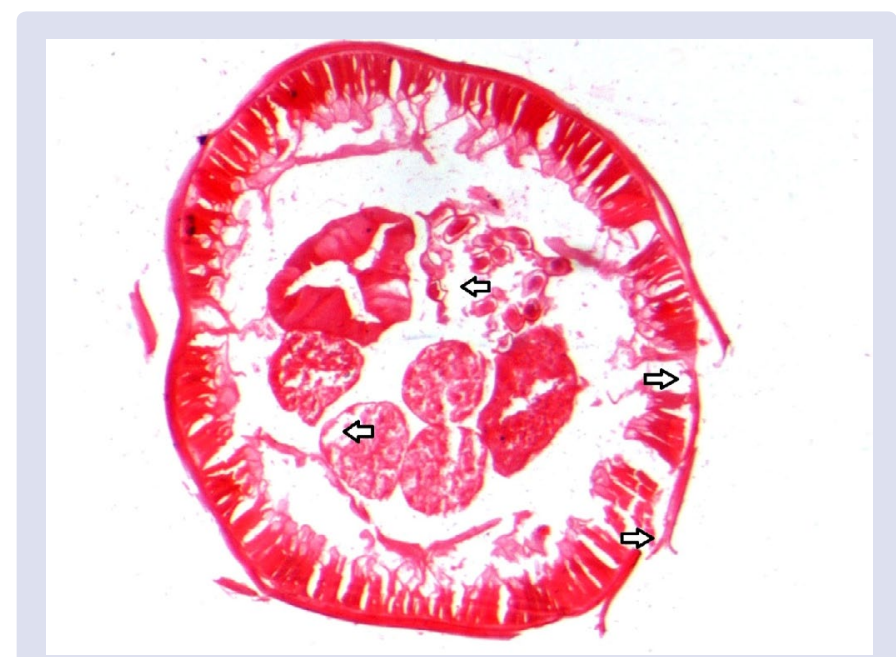

Figure 6: Transverse sections of female A. galli treated with $M$. pachycarpa root bark extract. Structural damages are evident, particularly on those indicated with arrows such as cuticle, epidermis, musculature, and uterine chambers. (x 200).

of ingesting food materials. Yet, like any other helminths, anthelmintic drugs act on them principally though transcuticular diffusion. ${ }^{19}$

The cuticle is chemically an extracellular matrix composed largely of minute proteins, of which collagen is the predominant, that are heavily crosslinked to form a rather dense multi-proteinaceous layer. Basically, the innermost fibrillar layer, consisting of the medial and basal layers, is composed exclusively of collagens; the middle matrix and outer cortex layers contain non-collagen protein $\mathrm{s}^{20}$. The underlying layer of cuticle, called the basal lamina or basement membrane, is also composed on collagen but of different amino acids that are actually more closely related to vertebrate collagens. ${ }^{21}$

Therefore, drug should target these cuticular proteins as a primary route of action ${ }^{22}$. Anthelmintic drugs exhibit different degrees of efficacy to penetrate the cuticle. For example, commonly used albendazole (ABZ) with higher lipophilicity is much more diffusible through the cuticle of Haemonchus contortus and Ascaris suum when compared to its derivative $\mathrm{ABZ}$ sulfoxide ${ }^{23}$. Ivermectin also enters through the cuticle in Caenorhaditis elegans, $H$. contortus and Oncocerca ochengi to primarily inhibit muscle contraction. ${ }^{24}$ Cyclotides, a family of plant peptides, directly attack the cuticle of $H$. contortus and Trichostrongylus colubriformis. ${ }^{25}$ Natural cysteine proteinases also exert anthelmintic activity by primarily attacking the cuticle in different roundworms. ${ }^{26,27}$ Extract of Acacia mearnsii was shown to cause shrinkage and severe destruction on the cuticle of $H$. contortus ${ }^{28}$. We have also shown that a related plant Acacia oxyphylla extract primarily acted through the cuticle to cause tissue damages in the internal musculature in $A$. galli. ${ }^{29}$ These evidences make clear that cuticle is the centre of attraction for studying the effects of anthelmintic agents.

The ultimate target tissue of drugs in roundworms is the muscles, and damage in the musculature can be seen as loss of structural disintegration on the cuticle on the external surface. Morantel, pyrantel and levamisole act on the synaptic junction of muscles and bind to acetylcholine receptors (AChR) in A. suum. ${ }^{30}$ Levamisole also targets $\mathrm{AChR}$ and additionally inhibits neurotransmitters such as GABA and glutamate in A. suum muscle. ${ }^{31}$ A combination of piperazine and a depsipeptide BAY 44-4400 caused degeneration of muscle fibres and vacuolisation of the epidermal layers in Heterakis spumosa. ${ }^{32,33}$ The damaging effects of $M$. pachycarpa on the muscles of the roundworm are not surprising because the plant extract has been shown to cause destabilisation of microtubules, which are vital components of cellular 
motility. ${ }^{34,35}$ The damaging effect of $M$. pachycarpa extract on A. galli is also apparently through inhibition of neuro-muscular signalling system. With evidence from other studies on tapeworm, these findings suggest that the plant extract contains anthelmintic compounds that are broad-spectrum acting on a diverse class of helminth parasites.

\section{CONFLICTS OF INTEREST}

None declared.

\section{REFERENCES}

1. Lalchhandama K. Mosquitocidal activity of Millettia pachycarpa on the larvae and eggs of Aedis aegypti. Annals of Biological Research. 2011;2(3):212-22.

2. Ye H, Fu A, Wu W, Li Y, Wang G, Tang M, et al. Cytotoxic and apoptotic effects of constituents from Millettia pachycarpa Benth. Fitoterapia. 2012;83(8):1402-8.

3. Harrison JJ, Dankyi E, Kingsford-Adaboh R, Ishida $H$. In search of new leads: a closer look at the therapeutic potential of the constituents of Millettia thonningii, Millettia pachycarpa and their structural analogues. International Journal of Pharmacy and Pharmaceutical Sciences. 2011;3(2):71-81.

4. Ye H, Chen L, Li Y, Peng A, Fu A, Song H, et al. Preparative isolation and purification of three rotenoids and one isoflavone from the seeds of Millettia pachycarpa Benth by high-speed counter-current chromatography. Journal of Chromatography A. 2008;1178(1-2):101-7.

5. Deyou T, Jang YP. A new prenylated isoflavone from the seeds of Millettia ferruginea ssp. ferruginea. South African Journal of Botany. 2018;117:155-7.

6. Chen F, Lu J, Chen Q, Guo J, Zhong S, Yan X, et al. Studies on the chemical constituents of thickfruit Millettia root (Millettia pachycarpa) I. Chinese Traditional and Herbal Drugs. 1999;30(1):3-5.

7. Lu J, Zeng J, Kuang Z, Chen F. Studies on the chemical constituents of thickfruit Millettia root (Millettia pachycarpa) (II). Chinese Traditional and Herbal Drugs. 1999;30(10):721-3.

8. Shao W, Zhu Y, Guan S, Zhong S, Chen F. Study on the chemical constituents of thickfruit Millettia root (Millettia pachycarpa). Natural Product Research and Development. 2001;13(1):1-4

9. Ye H, Xie C, Wu W, Xiang M, Liu Z, Li Y, et al. Millettia pachycarpa exhibits anti-inflammatory activity through the suppression of LPS-induced NO/iNOS expression. The American Journal of Chinese Medicine. 2014;42(04):949-5

10. Ye H, Zhong S, Li Y, Tang M, Peng A, Hu J, et al. Enrichment and isolation of barbigerone from Millettia pachycarpa Benth. using high-speed countercurrent chromatography and preparative HPLC. Journal of Separation Science. 2010;33(8):1010-7.

11. Li $X$, Wang $X$, Ye $H$, Peng $A$, Chen L. Barbigerone, an isoflavone, inhibits tumor angiogenesis and human non-small-cell lung cancer xenografts growth through VEGFR2 signaling pathways. Cancer Chemotherapy and Pharmacology. 2012;70(3):425-37.

12. Okamoto $Y$, Suzuki $A$, Ueda $K$, Ito $C$, Itoigawa $M$, Furukawa $H$, et al. Antiestrogenic activity of prenylated isoflavones from Millettia pachycarpa: implications for pharmacophores and unique mechanisms. Journal of Health Science. 2006;52(2):186-91.

13. Ito C, Itoigawa M, Kumagaya M, Okamoto $Y$, Ueda K, Nishihara T, et al. Isoflavonoids with antiestrogenic activity from Millettia pachycarpa. Journal of Natural Products. 2006;69(1):138-41.

14. Xue-Hui SU, Cong-Ying LI, Zhong YJ, Zhi-Peng YU, Yan-Fang LI, Liang B. A new prenylated chalcone from the seeds of Millettia pachycarpa. Chinese Journal of Natural Medicines. 2012;10(3):222-5.
15. Wang G, Qiu J, Xiao X, Cao A, Zhou F. Synthesis, biological evaluation and molecular docking studies of a new series of chalcones containing naphthalene moiety as anticancer agents. Bioorganic Chemistry. 2018;76:249-57.

16. Roy B, Lalchhandama K, Dutta B. Scanning electron microscopic observations on the in vitro anthelmintic effects of Millettia pachycarpa on Raillietina echinobothrida. Pharmacognosy Magazine. 2008;4(13):20-6.

17. Lalchhandama K, Roy B, Dutta B. Effects of Millettia pachycarpa on the trace metals and tegumental enzymes of Raillietina echinobothrida. Pharmacognosy Magazine. 2008;4(16):254-61.

18. Wright KA. The nematode's cuticle: its surface and the epidermis: function, homology, analogy: a current consensus. The Journal of Parasitology. 1987;73(6):1077-83.

19. Lanusse CE, Alvarez LI, Lifschitz AL. Gaining insights into the pharmacology of anthelmintics using Haemonchus contortus as a model nematode. Advances in Parasitology. 2016;93:465-518.

20. Lalchhandama K. On the structure of Ascaridia galli, the roundworm of domestic fowl. Science Vision. 2010;10(1):20-30.

21. Cox GN. Molecular and biochemical aspects of nematode collagens. The Journal of Parasitology. 1992; 78(1):1-5.

22. Page AP, Stepek G, Winter AD, Pertab D. Enzymology of the nematode cuticle: A potential drug target? International Journal for Parasitology. 2014;4(2):133-41.

23. Alvarez LI, Mottier ML, Lanusse CE. Drug transfer into target helminth parasites. Trends in Parasitology. 2007;23(3):97-104.

24. Yates DM, Portillo V, Wolstenholme AJ. The avermectin receptors of Haemonchus contortus and Caenorhabditis elegans. International Journal for Parasitology. 2003;33(11):1183-93.

25. Colgrave ML, Huang YH, Craik DJ, Kotze AC. Cyclotide interactions with the nematode external surface. Antimicrobial Agents and Chemotherapy. 2010;54(5):2160-6.

26. Luoga W, Mansur F, Buttle DJ, Duce IR, Garnett MC, Lowe A, et al. The relative anthelmintic efficacy of plant-derived cysteine proteinases on intestinal nematodes. Journal of Helminthology. 2015;89(2):165-74.

27. Phiri AM, De Pomerai DI, Buttle DJ, Behnke JM. A novel assay for the detection of anthelmintic activity mediated by cuticular damage to nematodes: validation on Caenorhabditis elegans exposed to cysteine proteinases. Parasitology. 2017;144(5):583-93.

28. Yoshihara E, Minho AP, Tabacow VBT, Cardim ST, Yamamura MH. Ultrastructura changes in the Haemonchus contortus cuticle exposed to Acacia mearnsii extract. Semina: Ciências Agrárias. 2015;36(6):3763-8.

29. Lalchhandama K, Roy B, Dutta BK. Anthelmintic activity of Acacia oxyphylla stem bark against Ascaridia galli. Pharmaceutical Biology. 2009;47(7):578-83.

30. Harrow ID, Gration KA. Mode of action of the anthelmintics morantel, pyrantel and levamisole on muscle cell membrane of the nematode Ascaris suum. Pesticide Science. 1985;16(6):662-72.

31. Brownlee DJ, Holden-Dye L, Walker RJ. Actions of the anthelmintic ivermectin on the pharyngeal muscle of the parasitic nematode. Ascaris suum. Parasitology. 1997;115(5):553-61.

32. Nicolay F, Harder A, von Samson-Himmelstjerna G, Mehlhorn H. Synergistic action of a cyclic depsipeptide and piperazine on nematodes. Parasitology Research. 2000;86:982-92.

33. An B, Zhang S, Yan J, Huang L, Li X. Synthesis, in vitro and in vivo evaluation of new hybrids of millepachine and phenstatin as potent tubulin polymerization inhibitors. Organic and Biomolecular Chemistry. 2017;15(4):852-62.

34. Huang X, Huang R, Li L, Gou S, Wang H. Synthesis and biological evaluation of novel chalcone derivatives as a new class of microtubule destabilizing agents. European Journal of Medicinal Chemistry. 2017;132:11-25. 


\section{GRAPHICAL ABSTRACT}

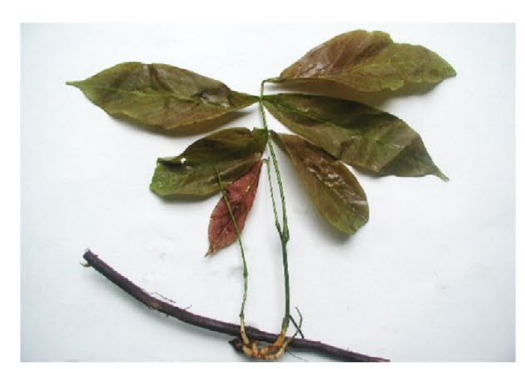

Millettia pachycarpa
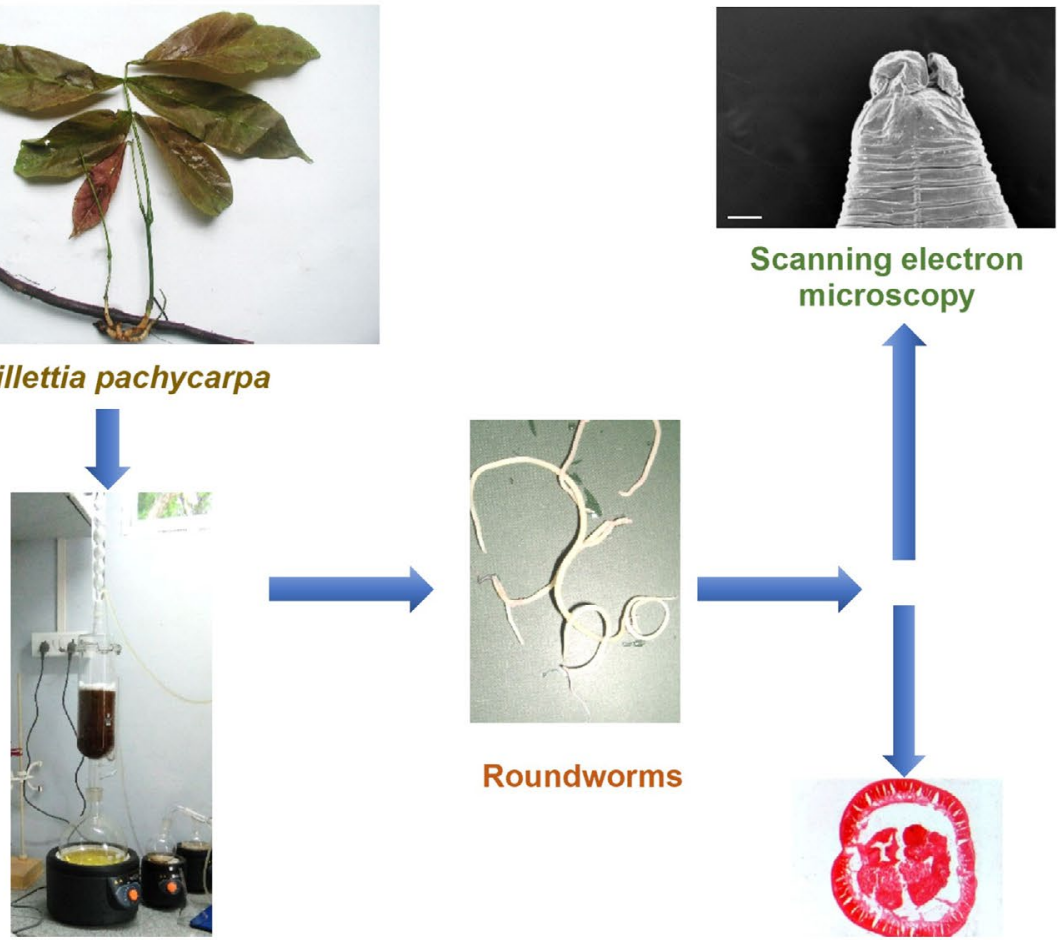

Scanning electron microscopy

Roundworms

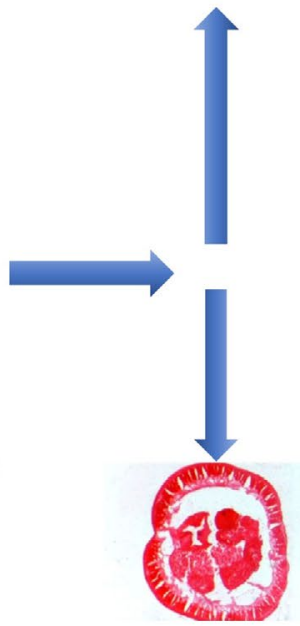

Methanol extract

Histology

\section{SUMMARY}

- Anthelmintic activity of the methanol extract of Milettia pachycarpa root bark is validated against an intestinal roundworm, Ascaridia galli. The extract showed concentration-dependent activity against the parasite as that of albendazole.

- Scanning electron microscopy revealed extensive damage on A. galli after treatment with the plant extract. Shrinkage of the cuticle, collapse of the lips and formation of cracks were described.

- Histology showed damages in the cuticular and muscular layers. Vacuolisation of the uterus and disintegration of the uterine wall were also seen.

- These anthelmintic effects indicate that the plant contains important compounds, which need further investigation to understand the exact chemical nature and mode of action.

\section{ABOUT AUTHOR}

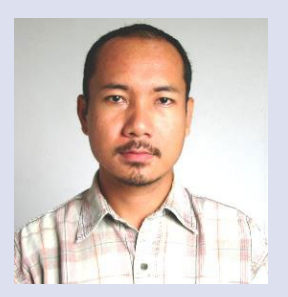

Kholhring Lalchhandama: $\mathrm{He}$ is an Associate Professor and Head of the Department of Life Sciences at Pachhunga University College, Aizawl, India.

Cite this article: Lalchhandama K. Anthelmintic Activity of Millettia pachycarpa Root Bark Extract on an Intestinal Roundworm, Ascaridia galli. Pharmacog J. 2019;11(6)Suppl:1428-33. 